\title{
Correction to: Disparities in Healthcare Utilization Among Adults with Obesity in the United States, Findings from the NHIS: 2006-2015
}

\author{
Judith D. Weissman ${ }^{1}$ (D) David Russell ${ }^{2}$ Patricia Ansah ${ }^{3} \cdot$ Melanie Jay $^{4,5}$
}

Published online: 18 March 2019

(C) Springer Nature B.V. 2019

\section{Correction to: Population Research and Policy Review https://doi.org/10.1007/s11113-018-09507-w}

In the original publication of the article the Table 1 header has been switched. The corrected Table is provided in this correction article.

The original article can be found online at https://doi.org/10.1007/s11113-018-09507-w.

\section{Judith D. Weissman}

Judithweissman@yahoo.com

1 Department of Molecular Imaging and Neuropathology, New York State Psychiatric Institute, New York, New York, USA

2 Department of Sociology, Appalachian State University, Boone, NC, USA

3 City University of New York, Brooklyn College, Kings County, USA

4 Department of Population Health and Medicine, New York University, New York County, New York City, USA

5 Veterans Health Affairs, New York Harbor, New York County, New York City, USA 


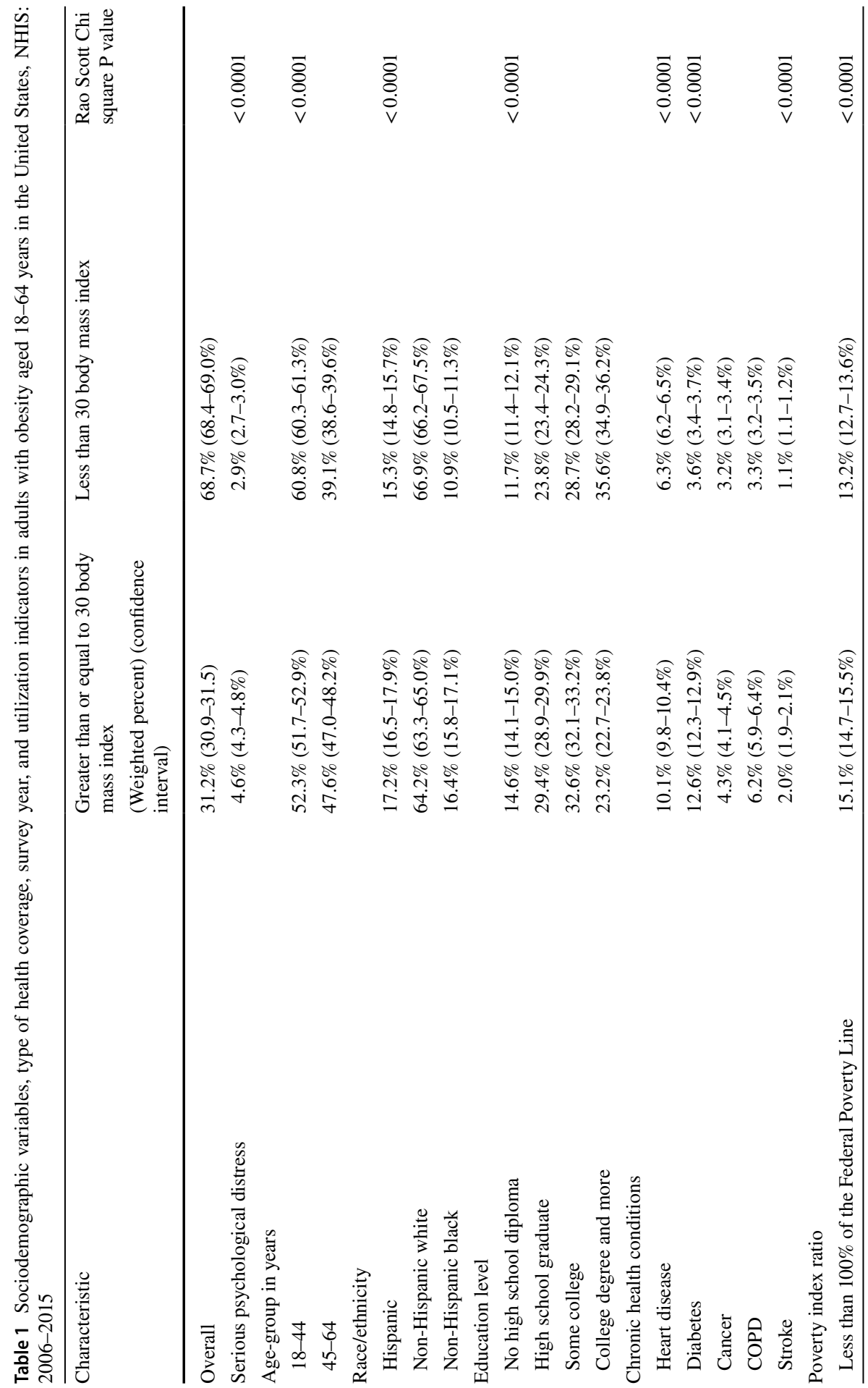




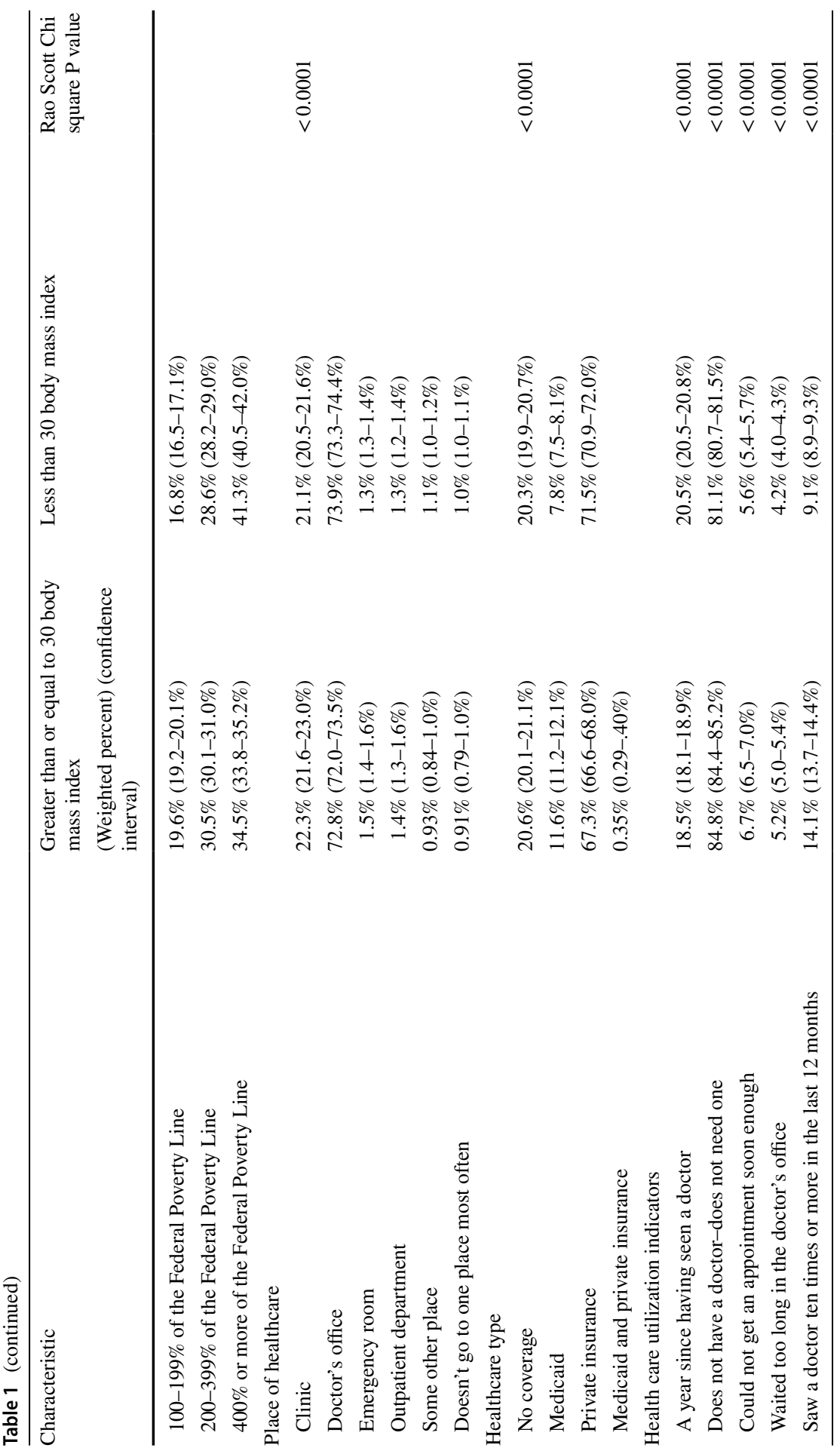


Publisher's Note Springer Nature remains neutral with regard to jurisdictional claims in published maps and institutional affiliations. 